\title{
Crystallization of Long-Spaced Precision Polyacetals II: Effect of Polymorphism on Isothermal Crystallization Kinetics
}

\author{
Xiaoshi Zhang ${ }^{1}$, Stephanie F. Marxsen ${ }^{1}$, Patrick Ortmann ${ }^{2}$, Stefan Mecking ${ }^{2}$, Rufina G. Alamo ${ }^{1^{*}}$ \\ ${ }^{1}$ Department of Chemical and Biomedical Engineering, FAMU-FSU College of Engineering, \\ 2525 Pottsdamer St, Tallahassee, Florida 32310-6046, United States \\ ${ }^{2}$ Chemical Materials Science, Department of Chemistry, University of Konstanz, \\ Universitätsstrasse 10, 78457 Konstanz, Germany
}

\section{Supporting Information}

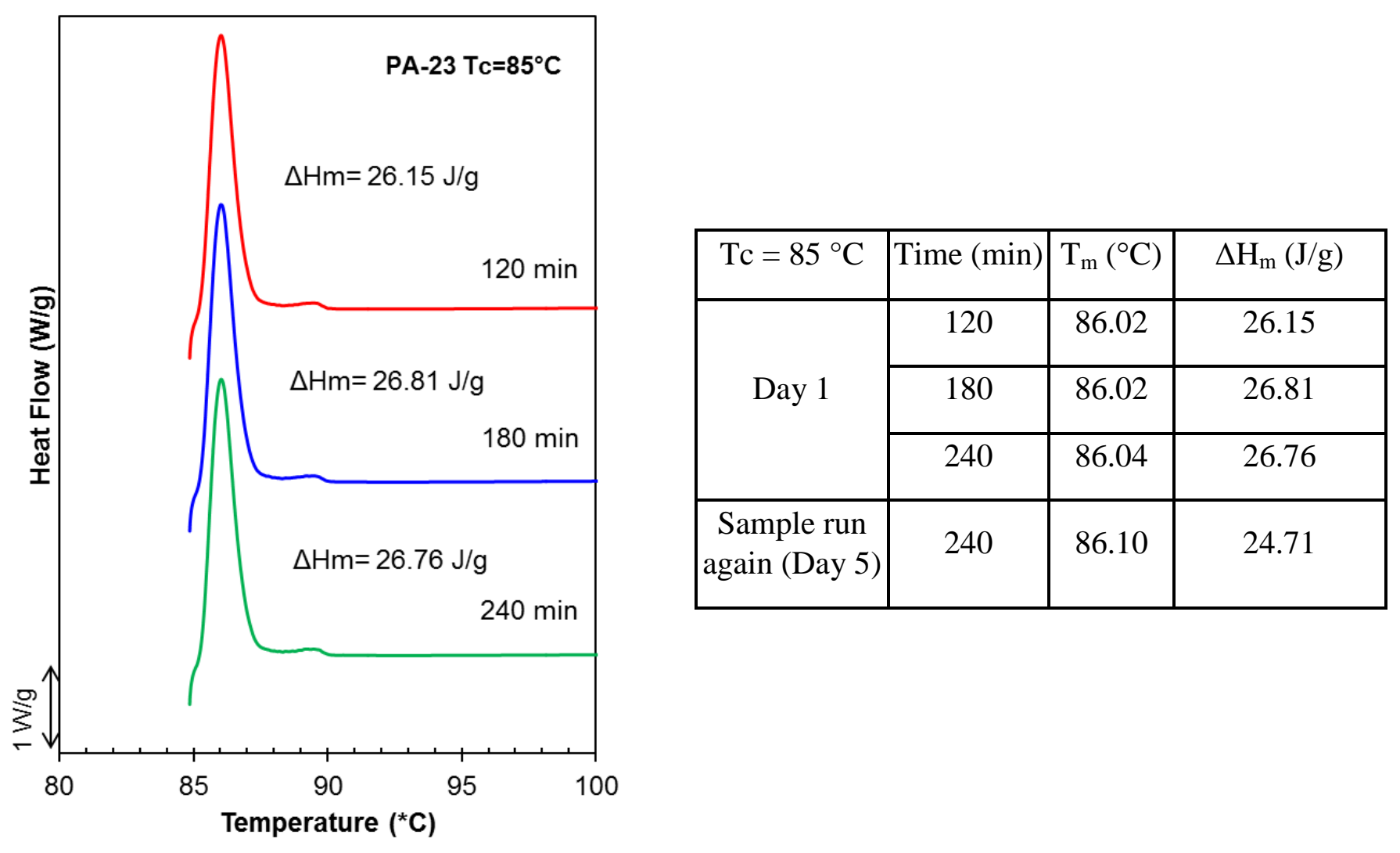

Figure SI 1 (a). DSC Melting endotherms of PA-23 isothermally crystallized at $85^{\circ} \mathrm{C}$ for different lengths of time. Melting peak and heat of fusion remain unchanged. 


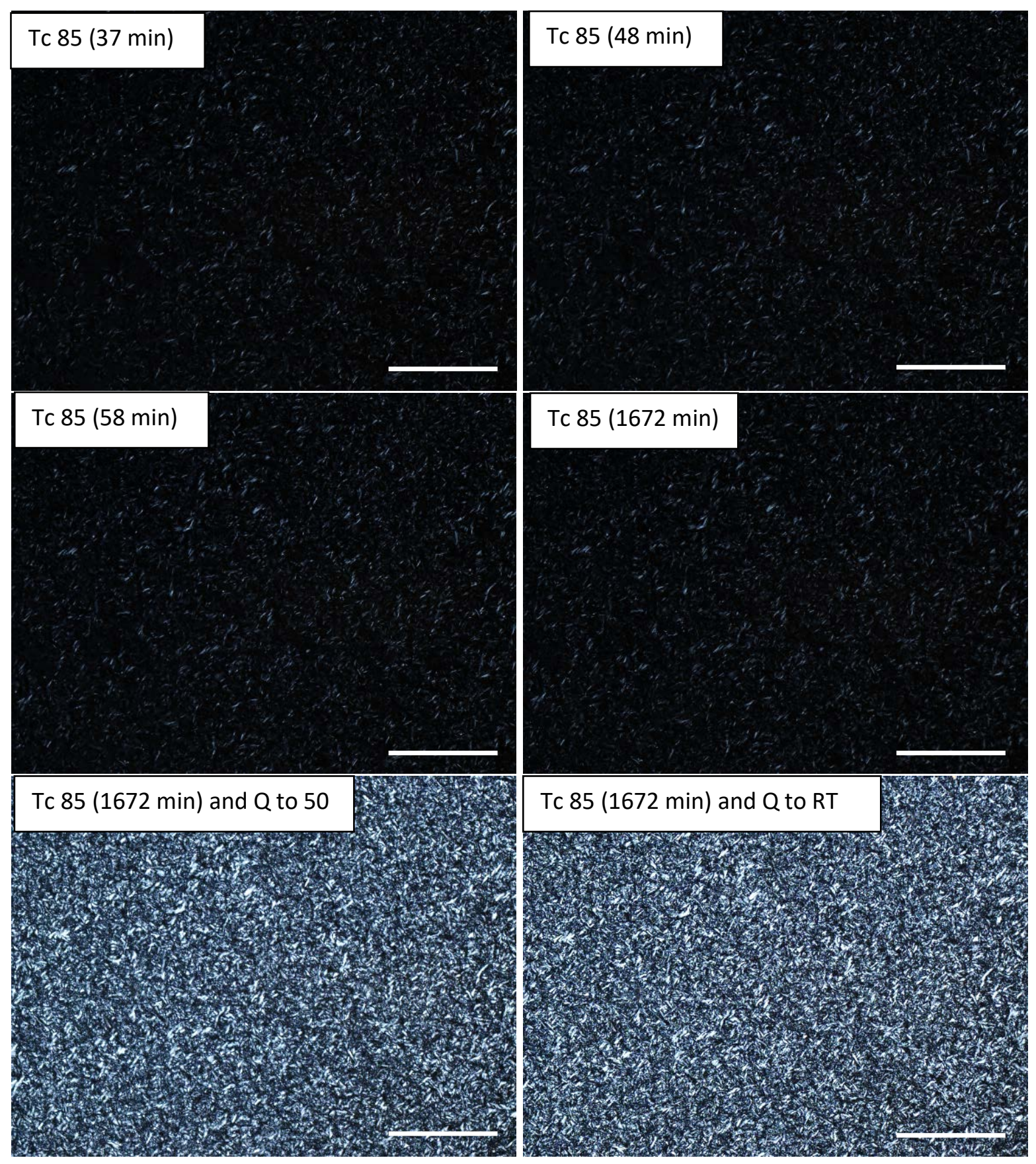




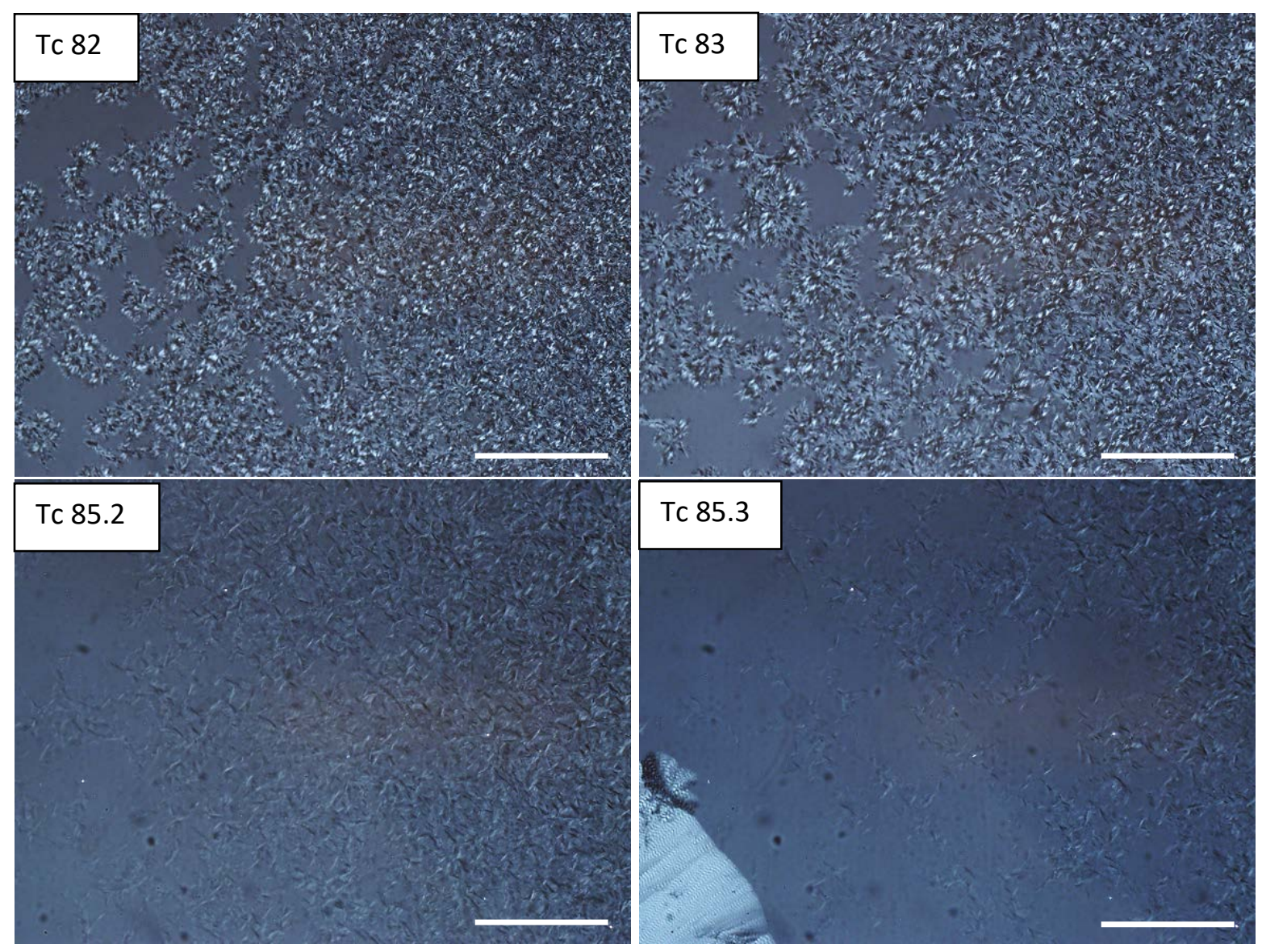

Figure SI 1 (b). Unchanged morphology with crystallization time of Form I of PA-23, Tc = 85 ${ }^{\circ} \mathrm{C}$ (even for holding times $>1000 \mathrm{~min}$ ). Additional crystallinity develops only after quenching to a lower temperature. Also shown are morphologies of Form I before the minimum of heat flow $\left(\mathrm{Tc}=82^{\circ} \mathrm{C}, 83^{\circ} \mathrm{C}\right.$ ), and at the inception of Form II (large spherulite at the lower left side of $\mathrm{Tc}=85.3^{\circ} \mathrm{C}$ and axialites of Form I, similar to the images shown in Figure 6 of the manuscript). The scale bar corresponds to $200 \mu \mathrm{m}$ 

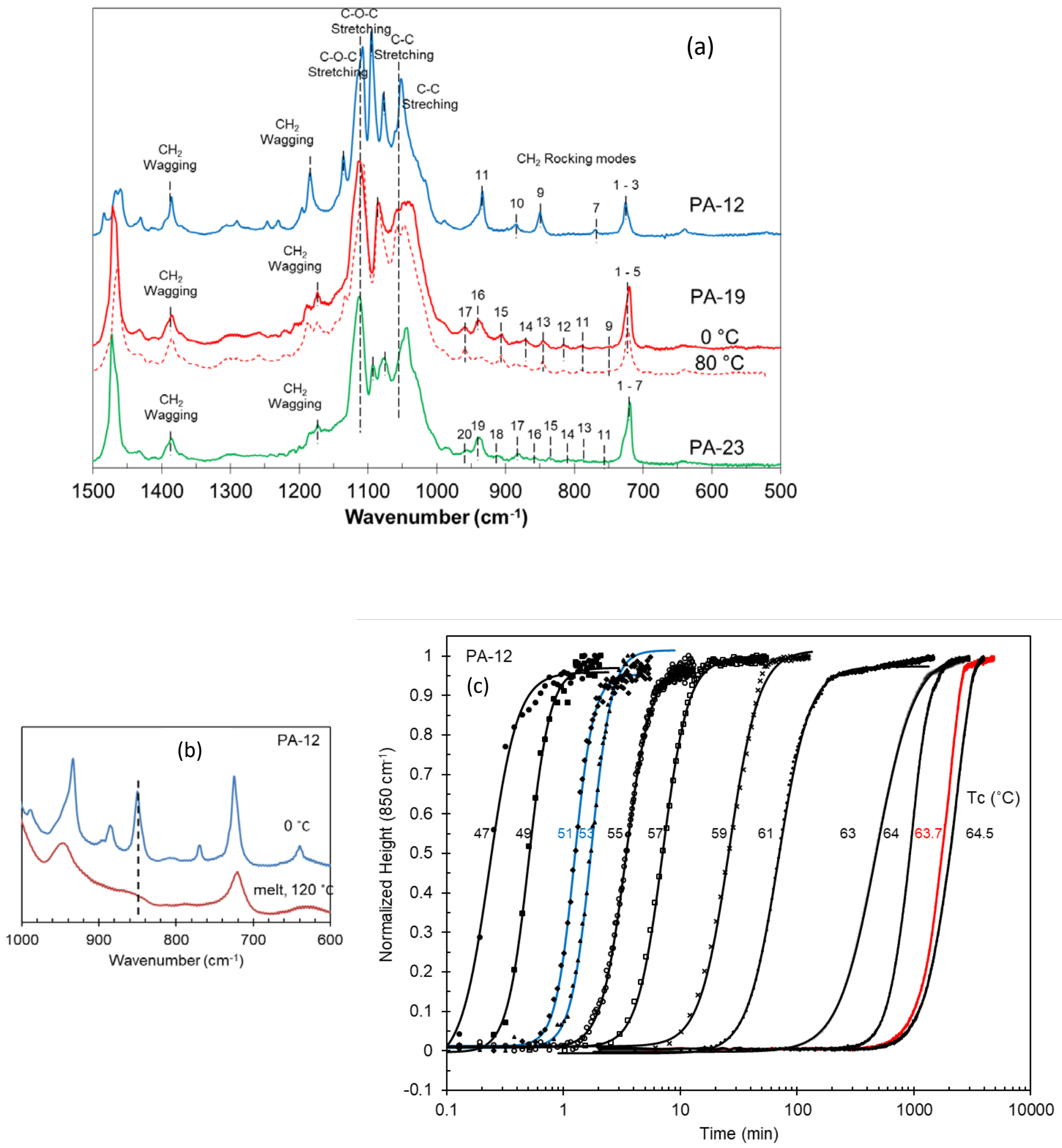

Figure SI 2. (a) FTIR spectra of the series of long-spaced polyacetals with assignments (Y. Li et al., Polymer 2011, 52, 2059-2069 and Zhang et al. J. Phys. Chem. B 2017, 121, 10166-10179). (b) $\mathrm{CH}_{2}$ Rocking modes region of PA-12 in the melt and the crystallines states. (c) The evolution of the intensity of the $850 \mathrm{~cm}^{-1}$ band was followed with time at different isothermal crystallization temperatures. 


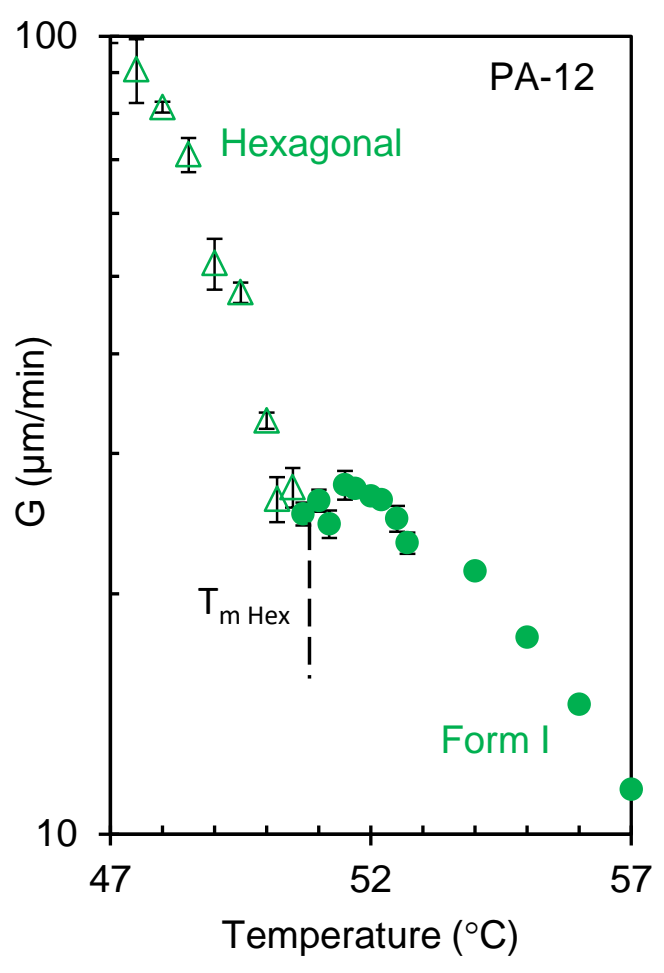

Figure SI 3. Linear growth rate versus crystallization temperature for PA-12 in the transition region from hexagonal (open triangles) to Form I (filled circles) 


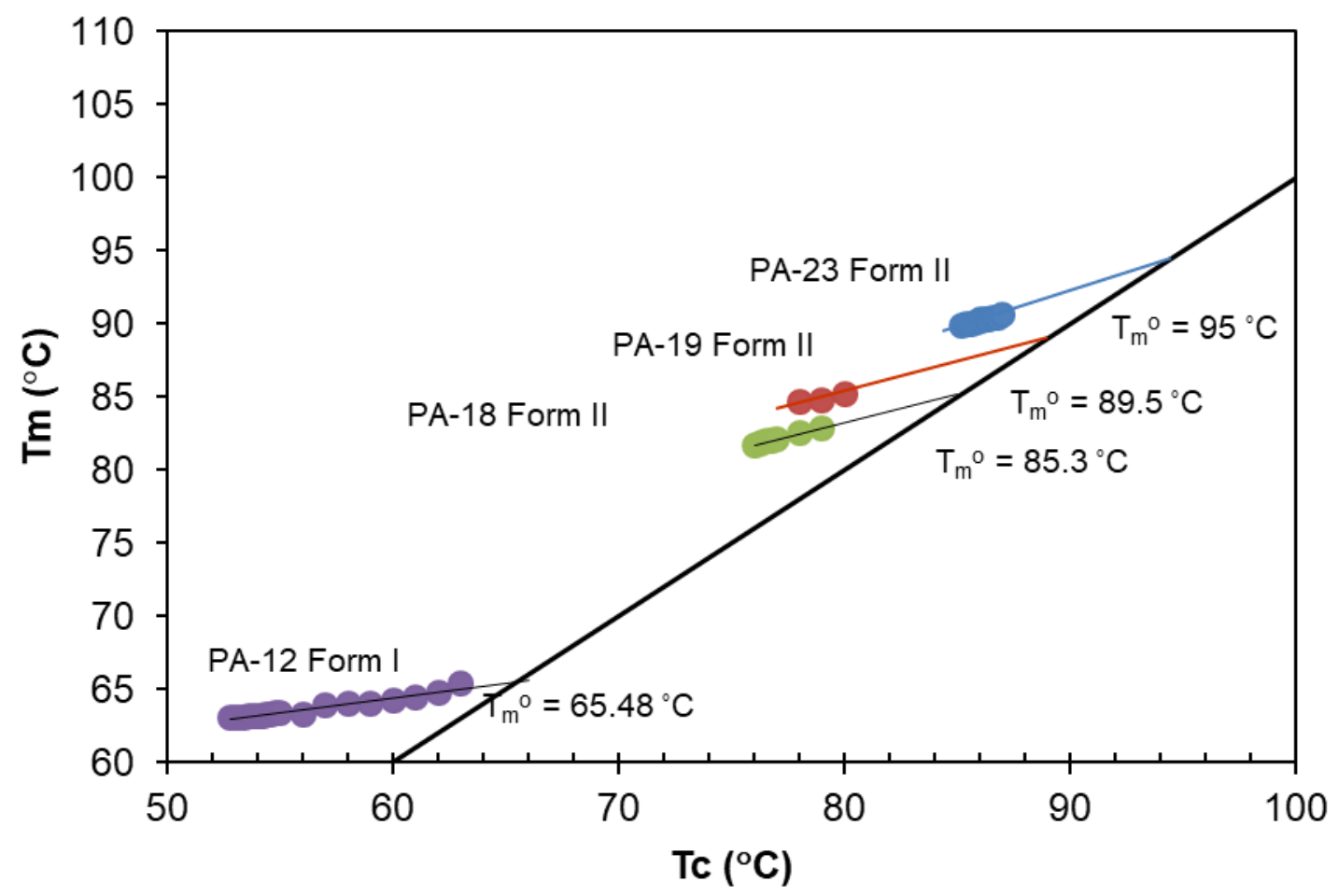

Figure SI 4. Estimation of $\mathrm{T}_{\mathrm{m}}{ }^{\mathrm{o}}$ using Hoffman-Weeks $\mathrm{Tm} / \mathrm{Tc}$ extrapolation. 